\title{
Heritability of size, a sexually selected character, and the response to sexual selection in a natural population of the southern green stink bug, Nezara viridula (Hemiptera: Pentatomidae)
}

\author{
Denson Kelly McLain
}

Department of Biology, Emory University, Atlanta, Georgia 30322 U.S.A.

\begin{abstract}
Using half-sib analysis and two dietary regimens, the heritability of size was estimated for the first generation offspring of field-collected southern green stink bugs, Nezara viridula, from a population in the southeastern U.S. Heritability estimates and actual size were larger under the condition of higher quality diet. A response to sexual selection was estimated using: (a) the estimate of heritability obtained from rearing under low quality diet (since this diet yields individuals of the same size as field bugs), and (b) the selection differential for size derived from random collections of mating and nonmating males in the natural population. Phenotypic evolution may occur in the study population if natural selection for size does not oppose sexual selection and if environmental conditions, such as food availability, do not mask genetic variation for size. Sampling of marked individuals revealed that a significant intensity of sexual selection is maintained during the season of adult activity. Correlations of size with longevity or number of parasites suggest natural selection also favours larger size. The results suggest that directional sexual selection and environmental heterogeneity may promote population differentiation as a consequence of differences in the exposure to selection of genetic variation for sexually selected traits.
\end{abstract}

\section{INTRODUCTION}

In many species of insects, larger males outcompete smaller males for access to females (Thornhill and Alcock, 1983). Since reproductive competition between males can be intense (Fincke, 1982; McCauley, 1983; McLain, 1986; McLain and Boromisa, 1987a), there is opportunity for sexual selection to promote phenotypic evolution (Arnold and Wade, 1984). Given sufficient genetic variation, sexual selection can not only promote rapid phenotypic evolution (Fisher, 1930; Lande, 1981), but can also reduce mean population fitness (Kirkpatrick, 1982; Lande, 1980a; Heisler, 1984).

In the absence of countervailing natural selection, strong sexual selection could deplete genetic variation (Williams, 1975; Maynard Smith, 1978) as is observed for other fitness characters (Harpending, 1979; Falconer, 1981). It is, therefore, of interest to determine if genetic variation for sexually selected characters exists in natural populations. Since sexual selection is usually directional (West-Eberhard, 1983; McLain and Boromisa, 1987b), the existence of genetic variation for sexually selected traits may indicate either the presence of countervailing natural selection, resulting in overall stabilising selection, or weak sexual selection on traits with polygenic inheritance (Lande, 1976, 1980b).

The present study examined the heritability of size, a trait shown to be sexually selected, in a Georgia population of the southern green stink bug, Nezara viridula L. (Hemiptera: Pentatomidae). In addition, a mark-recapture experiment was conducted to permit an estimation of the opportunity for sexual selection. Both males and females of the southern green stink bug are polygamous (McLain, 1980). Finally, the potential influence of natural selection on size was investigated by examining the correlation between size and (a) parasitisation levels, and (b) longevity.

\section{METHODS}

\section{Field study}

Field observations were made in mid-July through August, 1984, in an abandoned 1.5 ha. pasture in 
Cordele, Georgia. Snap beans, upon which the bugs fed, and fescue constituted most of the vegetation. Stink bugs were relatively abundant at the study site from June through September. Mating activity was unabated throughout this period. Mating and nonmating males were sampled without bias (as encountered on parallel transects through the site) and measured with calipers to the nearest $0.5 \mathrm{~mm}$ across the width of the pronotum, as the index of size. Thus, the selection differential, $S$, can be calculated as $S=$ mean of mating malesmean of mating + nonmating males, and the change in population mean, $R$, estimated as $R=h^{2} S$ where $h^{2}$ is the heritability of size (Manly, 1985).

The intensity of sexual selection, $I_{s}$, was calculated from mark recapture data on 118 males observed five times each. Initially, 400 males had been individually marked with 1-3 dots of model airplane paint applied to the pronotum, scutellum, or hemilytra. Most marked males were observed on only $1-2$ of the 34 sampling dates. $I_{s}$, which is best considered an opportunity for selection (Crow, 1958), is calculated as the variance in the number of matings divided by the square of the mean number of matings (Arnold and Wade, 1984). The statistical significance of the estimate of $I_{s}$ was tested by comparing the variance of the actual data set with the variance of a null data set with Levene's test (McLain, 1986). The null data set was constructed by assigning matings to individuals at random with the restrictions that the total number of matings assigned equalled the number observed (therefore the mean is conserved) and that no individual received more than 5 matings ( $=$ the number of observations per individual).

The degree of parasitization of males by the tachinid (Diptera) parasitoid, Trichopoda pennipes, was indexed as the number of eggs attached to the surface of the exoskeleton.

\section{Heritability of size}

A laboratory colony was established from the eggs of 32 field collected females. The progeny of these females constituted the parental generation for heritability estimates. For a single female parent, 100 nymphs from the first two egg masses laid after mating were sequestered into 10 separate groups of 10 and reared in 1-litre jars. A single male was chosen at random from each jar and measured across the width of the pronotum. Five jars were supplied with a high quality diet in which 3 fresh snap beans and three shelled raw peanuts were provided every other day. The other 5 jars were similarly stocked except that fresh food was supplied only once per week. Here, a lower quality diet resulted since the food dried out several days before replenishment. Ninety males were utilised, each mated to 2 females. All parents were 7-10 day old virgins at the initiation of the experiments. Stink bugs were reared at $27 \pm 2^{\circ} \mathrm{C}$, with a $16 \mathrm{~L}$ : $8 \mathrm{D}$ photophase, and under $40-50$ per cent RH.

Heritability was estimated for size using the analysis of half-sib and full-sib families (Falconer, 1981; Bulmer, 1985). Since each male was mated twice, the sources of variation in progeny size are: (a) between males, (b) between females within males, and (c) within families. To minimise environmental contributions to within family correlations, the measured progeny constituting a family were reared in separate jars as described above. The correlation between half sibs is $p_{h}=$ $\left(M_{1}-M_{2}\right) /\left(M_{1}+M_{2}+2 M_{3}\right)$ while that between full sibs is $p_{f}=\left(M_{1}+M_{2}-2 M_{3}\right) /\left(M_{1}+M_{2}+2 M_{3}\right)$ where $M_{1}$ is the between males mean square, $M_{2}$ is the between females within males mean square, and $M_{3}$ is the within families mean square (Bulmer, 1985). The paternal component of heritability is $4 P_{h}$ while the maternal component is $8\left(M_{2}-\right.$ $\left.M_{3}\right) /\left(M_{1}+M_{2}+2 M_{3}\right) \quad$ (Falconer, 1981). The male + female estimate of heritability is $2 p_{f}$ (Falconer, 1981). Complex expressions yielding the approximate variance for estimates of heritability are given in Bulmer (1985).

\section{Longevity}

The association between size and longevity was estimated from laboratory data on the progeny of field-collected females. Single males were housed in 1-litre jars and supplied with high quality diets, as described above, for 45 days following the final moult. The proportion of males surviving was recorded for three subsets of males based on size, those with pronotal width less than $(n=55)$, equal to $(n=47)$, and greater than $(n=38) 6.75 \mathrm{~mm}$.

\section{RESULTS}

\section{Size and copulatory success}

The size of mating males $(x=6.92 \mathrm{~mm}, S D=$ $0.39 \mathrm{~mm}, n=221)$ was significantly larger $(P<$ $0.05, t=5.45)$ than the size of nonmating males $(x=6.70 \mathrm{~mm}, S D=0.39 \mathrm{~mm}, n=179)$. Thus, the selection differential is $0.10 \mathrm{~mm}$ or 0.26 phenotypic standard deviations.

The measured intensity of sexual selection, $I_{s}$, was 1.24 (mean number of matings per male 
observed $5 \times, 1 \cdot 076, S D=1 \cdot 199$ ). The null value for $I_{s}$ was $0 \cdot 843$, which represents significantly less variation in copulatory success than was actually observed ( $t=2 \cdot 90$, Levene's test).

For the 118 marked males observed $5 \times$, there was a significant linear correlation between male size and the number of copulations observed $(r=$ $0 \cdot 26, P<0 \cdot 05)$. However, there was no positive correlation between male size and the degree of parasitization $(r=0.09, P>0.05)$. In fact, parasitisation levels are greatest for males of intermediate size (fig. 1).

In the laboratory, a higher proportion of large males $(=0.97)$ survived 45 days after the final moult than did intermediate $(=0.89)$ or small $(=0.67)$ males. The association between longevity and size was statistically significant $(P<0 \cdot 05$, Chisquare $=16 \cdot 91)$.

\section{Heritability of size}

Estimates of genetic variation for size were significantly greater than zero for both dietary regimes $(P<0 \cdot 05 ;$ table 1$)$. However, the amount of genetic variation expressed (heritability) was approximately $2 \times$ greater under conditions of high quality diet than low quality diet.

Heritability estimates based on full- or half-sib correlations were nearly identical (table 1). Also, maternal and paternal contributions to genetic variation in size were similar.

The average size of males reared with the higher quality diet $(x=6.95 \mathrm{~mm}, S D=0.30)$ was significantly larger $(P<0.05, t=11.09)$ than the average under the lower quality diet $(x=6.78 \mathrm{~mm}$, $S D=0 \cdot 35$ ). Note that under the lower quality diet the mean size was very similar to the mean size of all males in the field (6.78 laboratory versus 6.82 field; for difference between the means $t=1 \cdot 76$, $P>0.05)$.

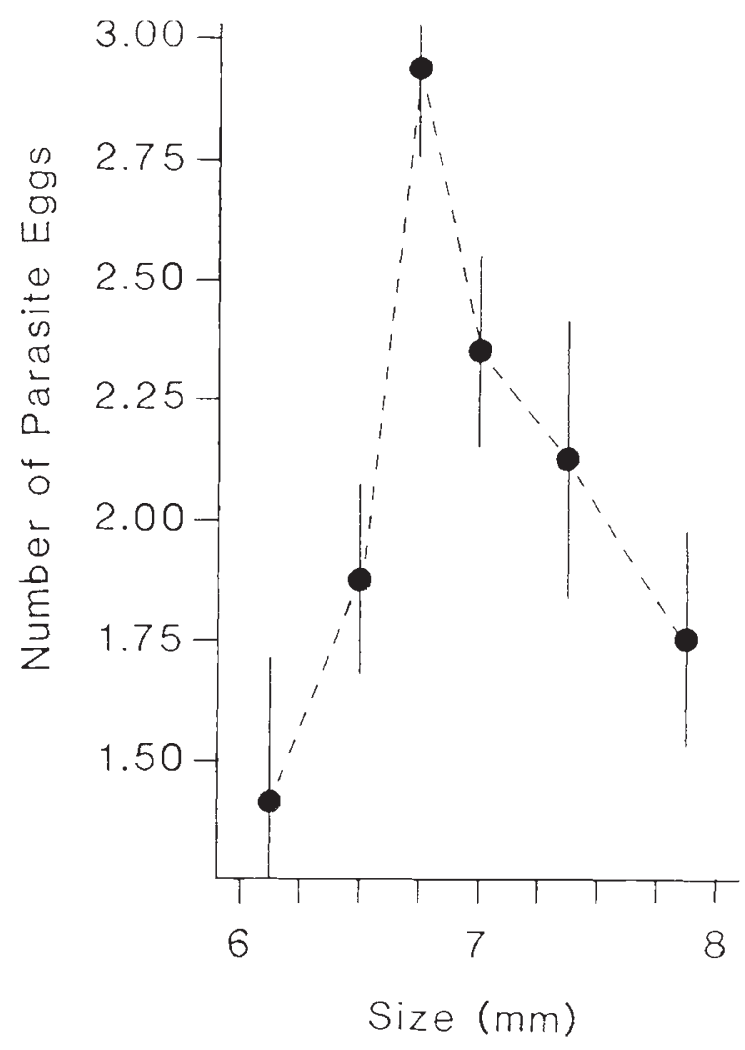

Figure 1 Mean and standard error of the number of parasitoid eggs on adult male stink bugs as a function of male size (pronotal width, in $\mathrm{mm}$ ).

\section{DISCUSSION}

The results reveal significant heritability for size, a sexually selected character, in the southern Georgia population of the southern green stink bug. The similarities in $h^{2}$ estimates based on the correlation between half- $\left(h^{2}=4 p_{h}\right)$ and full-sibs $\left(h^{2}=\right.$

Table 1 Sources of variation and heritability estimates for size of stink bugs reared with high and low quality diets. $S D=$ standard deviation. $S E=$ standard error

\begin{tabular}{|c|c|c|c|c|c|c|c|}
\hline Source of variation & df & mean square & $p_{h}(S D)$ & $p_{f}(S D)$ & $h_{q}^{2}$ & $h_{\delta}^{2}$ & $h_{8+\delta}^{2}(\mathrm{SE})$ \\
\hline \multicolumn{8}{|l|}{ High quality } \\
\hline $\mathrm{M}_{1}$ Between males & 89 & $0 \cdot 905$ & $0 \cdot 155(0.071)$ & $0.295(0.073)$ & 0.621 & 0.561 & $0.591(0.147)$ \\
\hline $\mathrm{M}_{2}$ Between females within males & 90 & 0.555 & & & & & \\
\hline $\mathrm{M}_{3}$ Within families & 720 & $0 \cdot 397$ & & & & & \\
\hline \multicolumn{8}{|l|}{ Low quality } \\
\hline $\mathrm{M}_{1}$ Between males & 89 & 0.595 & $0.086(0.061)$ & $0.152(0.062)$ & 0.345 & $0 \cdot 263$ & $0 \cdot 304(0 \cdot 125)$ \\
\hline $\mathbf{M}_{2}$ Between females within males & 90 & 0.440 & & & & & \\
\hline $\mathbf{M}_{3}$ Within families & 720 & $0 \cdot 381$ & & & & & \\
\hline
\end{tabular}


$2 p_{f}$ ) and estimates based on maternal versus paternal contributions to genetic variance suggest, respectively, additive genetic variation for size, and the absence of significant maternal inheritance.

The association between size and long-term copulatory success results in a significant opportunity for sexual selection $\left(I_{s}=1 \cdot 24\right)$ to effect phenotypic change. The statistically significant value for $I_{s}$ indicates that copulatory success does not even out over time, an insight which could not have been gained by examining the population over a short period of time. Larger males are also more successful in sperm competition in multiplyinseminated females (McLain, 1985).

Parasitisation of the southern green stink bug by the tachinid fly greatly reduces longevity and fertility (Shahjahan, 1968). Since longevity, which is correlated with size (in the laboratory, at least), is probably strongly correlated with lifetime copulatory success, and since parasitisation levels are not greater in larger males, no countervailing natural selection is detected which might oppose directional sexual selection on size. Unfortunately, there are no data on the relationship between development time and size. Natural selection could oppose larger size if this prolonged maturation time. However, increased development time is not likely to prolong exposure to vertebrate predators or parasitoids since nymphs and adults utilise the same chemical defences (Staddon, 1979) the efficacy of which is a function of insect size (McLain, 1980), and since the tachinid parasitoid is attracted only to mature males emitting sex pheromones (Harris and Todd, 1980). Thus, it is likely that sexual selection and natural selection favour large size in males. Natural selection also favours large size in females since fecundity, fertility, and longevity are positively correlated with size (McLain, 1985).

Therefore, the response of the population to sexual selection can be estimated as $R=h^{2} S / 2$, the product of heritability and the selection differential (Manly, 1985). The selection differential is divided by two since the sexual selection acts only on males. The heritability of size is a function of the quality of the diet, and possibly other factors such as temperature. Since the average size of males reared on the low quality diet is the same as that for field collected males, it is more appropriate to estimate the response to selection using the estimate of $h^{2}$ derived from individuals reared on the low quality diet. Thus, the response to sexual selection is $0 \cdot 30\left(=h^{2}\right) \times$ $0 \cdot 26 / 2(=$ standardised selection differential $/ 2)=$ 0.04 phenotypic standard deviations/generation.
Apparently, the quality of the diet limits the expression of genetic variation so that most of the variation in size observed in the natural population in Georgia is environmentally derived. A consequence of this is that selection on size is less effective and genetic variation will be depleted more slowly. This may account for the persistence of genetic variation in the study population. It is possible that under severe environmental conditions, such as those which might result in starvation of many individuals, genetic variation in size would be masked completely by environmental variation.

There is an interesting potential evolutionary consequence of the effect of the environment on the expression of genetic variation for sexually selected characters. Sexual selection could consistently select for some directional characteristic, such as size, colouration, pheromone composition, etc., across a species' geographic range. However, due to environmental heterogeneity the efficiency of selection could vary tremendously. If genetic variation could be maintained, as from gene flow, in populations where genetic variation is exposed to selection, population differentiation and speciation could occur. West-Eberhard (1983) argues that speciation is frequently a consequence of sexual selection acting in different directions in different populations. The present results suggest that the directions of selection need not vary, but that only the intensity need vary, for sexual selection to promote differentiation.

\section{REFERENCES}

ARNOLD, S. J. AND WADE, M. J. 1984. On the measurement of natural and sexual selection: theory. Evolution, 38, 709-719.

BULMER, M. J. 1985. The mathematical Theory of Quantitative Genetics. Clarendon Press, Oxford, 254 pp.

CROW, J. F. 1958. Some possibilities for measuring selection intensities in man. Hum. Biol., 30, 1-13.

FALCONER, D. S. 1981. Introduction to Quantitative Genetics. Longman House, London, 340 pp.

FINCKE, O. M. 1982. Lifetime mating success in a natural population of the damselfly, Enallagma hageni (Walsh) (Odonata: Coenargrionidae). Behav. Ecol. Sociobiol, 10, 293-302.

FISHER, R. A. 1930. The Genetical Theory of Natural Selection. Oxford University Press (Clarendon), London.

HARPENDING, H. C. 1979. The population genetics of interaction. Am. Nat., 113, 622-630.

HARRIS, V. E. AND TODD, J. W. 1980. Male mediated aggregation of male, female, and fifth instar southern green stink bugs and concomitant attraction of a tachinid parasite, Trichopoda pennipes (F.). Entomol. Exper. et Appl., 27, 1-10.

HEISLER, I. L. 1984. A quantitative genetic model for the origin of mating preferences. Evolution, 38, 1283-1295.

KIRKPATRICK, M. 1982. Sexual selection and the evolution of female choice. Evolution, 36, 1-12. 
LANDE, R. 1976. The maintenance of genetic variability by mutation in a polygenic character with linked loci. Genet. Res., 26, 221-235.

LANDE, R. $1980 a$. Sexual dimorphism, sexual selection, and adaptation in polygenic characters. Evolution, 34, 292-305.

LANDE, R. $1980 b$. Genetic variation and phenotypic evolution during allopatric speciation. Am. Nat., 116, 463-479.

LANDE, R. 1981. Models of speciation by sexual selection on polygenic traits. Proc. Natl. Acad. Science (USA), 78, 37213725 .

MANLY, B. F. J. 1985. The Statistics of Natural Selection. Chapman and Hall, London, $484 \mathrm{pp}$.

MAYNARD SMITH, J. 1978. The Evolution of Sex. Cambridge University Press, Cambridge, $222 \mathrm{pp}$.

MCCAUlEy, D. E. 1983. An estimate of the relative opportunities for natural and sexual selection in a population of milkweed beetles. Evolution, 37, 701-707.

MCLAIN, D. K. 1980. Female choice and the adaptive significance of prolonged copulation in Nezara viridula (Hemiptera: Pentatomidae). Psyche, 87, 325-336.

MCLAIN, D. K. 1985. Male size, sperm competition, and the intensity of sexual selection in the southern green stink bug, Nezara viridula (Hemiptera: Pentatomidae). Ann. Ent. Soc. Am., 78, 86-89.
MCLAIN, D. K. 1986. Null models and the intensity of sexual selection. Evol. Thoery, 8, 49-51.

MCLAIN, D. K. AND BOROMISA, R. D. $1987 a$. Interrelationship between male choice, fighting ability, assortative mating and the intensity of sexual selection for the milkweed longhorn beetle. Behav. Ecol. Sociobiol. 20, 239-246.

MCLAIN, D. K. AND BOROMISA, R. D. 1987 b. Stabilizing sexual selection and density-dependent correlates of copulatory success in the ambush bug, Phymata wolffi (Hemiptera: Roduviidae). Am. Midl. Nat., 117, 94-102.

SHAHJAHAN, M. 1968. Superparasitization of the southern green stink bug by the tachinid parasite Trichopoda pennipes and its effect on host survival. J. Econ. Ent., 61, 1088-1091.

STADDON, B. W. 1979. The scent glands of Heteroptera. Rec. Adv. Insect Physiol., 14, 351-419.

THORNHILL, R. AND ALCOCK, J. 1983. The Evolution of Insect Mating Systems, Harvard University Press, Cambridge, Mass.

WEST-EBERHARD, M. J. 1983. Sexual selection, social competition, and speciation. Quart. Rev. Biol., 58, 155-183.

Williams, G. C. 1975. Sex and Evolution. Princeton University Press, Princeton. 